\title{
Tetrakis(triphenylarsine oxide)copper(II) Bis[dichlorocuprate(I)]
}

\author{
By R. H. P. Francisco, R. H. de Almeida Santos and J. R. Lechat \\ Instituto de Física e Química de São Carlos, Universidade de São Paulo, CP 369, 13560 São Carlos, São Paulo, \\ Brazil
}

AND A. C. MASSABNI

Instituto de Química de Araraquara, UNESP, CP 174, 14800 Araraquara, São Paulo, Brazil

(Received 23 May 1980; accepted 19 August 1980)

\begin{abstract}
Cu}\left(\mathrm{C}_{18} \mathrm{H}_{15} \mathrm{AsO}\right)_{4}\right]^{2+} .2\left[\mathrm{CuCl}_{2}\right]^{-}$, monoclinic, $P 2_{1} / c, a=13.315(2), \quad b=20.162(4), c=$ 17.761 (2) $\AA, \beta=134.25(3)^{\circ}, V=3415$ (1) $\AA^{3}, Z=$ $2, D_{m}=1.59$ (flotation), $D_{x}=1.577 \mathrm{Mg} \mathrm{m}^{-3}$. The final $R$ was 0.045 for 3357 observed reflections. The $\mathrm{Cu}^{\text {II }}$ is coordinated to four $\mathrm{O}$ in a square-planar arrangement and the $\mathrm{Cu}^{\mathrm{I}}$ is coordinated to two $\mathrm{Cl}$ in a linear structure.
\end{abstract}

Introduction. The preparation and the spectral properties of a yellow-brown complex with empirical formula $\left[\mathrm{Cu}\left(\mathrm{tpa}_{\mathrm{s}} \mathrm{O}\right)_{2} \mathrm{Cl}_{2}\right]\left(\mathrm{tpa}_{\mathrm{s}} \mathrm{O}=\right.$ triphenylarsine oxide) have been reported (Goodgame \& Cotton, 1961; Rodley, Goodgame \& Cotton, 1965). In an attempt to prepare this compound according to the procedure described by Goodgame \& Cotton a yellow-brown complex was in fact obtained, but it analysed as $2 \mathrm{CuCl}_{2} \cdot 3\left(\mathrm{tpa}_{\mathrm{s}} \mathrm{o}\right)$. On the other hand, recrystallization of this complex from anhydrous acetone yields blue crystals of a new complex with empirical formula $\mathrm{Cu}_{3} \mathrm{Cl}_{4} \cdot 4\left(\mathrm{tpa}_{\mathrm{s}} \mathrm{O}\right)$. A complex with the same colour and empirical formula was studied by Nyholm (1951) starting from $\mathrm{CuCl}_{2}$ and methyldiphenylarsine. The complex was formulated as $\left[\mathrm{Cu}\left(\mathrm{mdpa}_{\mathrm{s}} \mathrm{O}\right)_{4}\right]\left[\mathrm{CuCl}_{2}\right]_{2}$, where $\mathrm{mdpa}_{\mathrm{s}} \mathrm{O}$ is methyldiphenylarsine oxide, suggesting that copper would be present as $\mathrm{Cu}^{\mathrm{I}}$ and $\mathrm{Cu}^{\mathrm{II}}$. Although this formulation seems plausible and could also apply to the $\mathrm{Cu}_{3} \mathrm{Cl}_{4} .4\left(\mathrm{tpa}_{\mathrm{s}} \mathrm{O}\right)$ complex it was felt that more conclusive evidence should be obtained concerning the copper coordination. Hence, an X-ray investigation of the latter complex was undertaken to elucidate its structural situation and to confirm the presence of copper in two oxidation states.

A crystal $0.2 \times 0.3 \times 0.15 \mathrm{~mm}$ was mounted at random on an automatic CAD-4 diffractometer. Cell dimensions were determined by a least-squares fit of settings for 25 reflections $( \pm h k l)$. Intensity measurements were carried out up to $\theta=75^{\circ}$ using the $\omega / 2 \theta$ scan mode and graphite-monochromated $\mathrm{Cu} K \alpha$ radiation. 4345 unique reflections were measured, of

$0567-7408 / 81 / 010232-03 \$ 01.00$ which 3357 were considered observed $[I>3 \sigma(I)]$ and retained for use in the structure analysis.

Lorentz and polarization corrections were applied but no absorption correction $\left[\mu\left(\mathrm{Cu} K(x)=4.02 \mathrm{~mm}^{-1}\right]\right.$ was made.

The structure was solved by application of the multi-solution weighted tangent formula (Germain, Main \& Woolfson, 1971) to the reflections with $E>$ 1.70. An $E$ map based on the solution with the highest absolute figure of merit (1.008) and the lowest residual index $(25.88)$ revealed the positions of one $\mathrm{Cu}$ and two As atoms.

The remaining non-hydrogen atoms of the organicligand molecules were located by successive differenceFourier calculations. At this point, a difference-Fourier synthesis unambiguously showed the dichlorocuprate ion.

The refinement was by minimization of $\sum w\left(k\left|F_{o}\right|-\right.$ $\left.\left|F_{c}\right|\right)^{2}$ through iterative full-matrix least-squares calculations including all data. Weights $w_{i}=\left[\sigma_{o i}^{2}+\right.$ $\left.\left(0.05 F_{o i}^{2}\right)^{2}\right]^{-1}$ (where $\sigma_{o i}^{2}$ was the variance based on counting statistics) were assigned to observed reflections ( $w_{i}=0$ for unobserved).

The refinement was conducted until all atomicparameter shifts were smaller than their standard deviations. The final unweighted $R$ factor omitting unobserved reflections was 0.045 , and including them, 0.048.*

Anisotropic temperature factors were assigned to all non-hydrogen atoms. Neutral-atom complex scattering factors were used (International Tables for X-ray Crystallography, 1974). Table 1 gives the heavy-atom coordinates.

\footnotetext{
* Lists of structure factors, anisotropic thermal parameters and bond distances and angles in the organic-ligand molecule have been deposited with the British Library Lending Division as Supplementary Publication No. SUP 35598 (22 pp.). Copies may be obtained through The Executive Secretary, International Union of Crystallography, 5 Abbey Square, Chester CH1 2HU, England.
}

(C) 1981 International Union of Crystallography 
Table 1. Fractional atomic coordinates $\left(\times 10^{5}\right.$ for As and $\mathrm{Cu}, \times 10^{4}$ for $\mathrm{Cl}, \mathrm{O}$ and $\mathrm{C}$ ) with their e.s.d.'s in parentheses

The $B_{\text {eq }}$ values are the equivalent isotropic temperature factors (Hamilton, 1959).

$\begin{array}{lccrc} & x & y & z & B_{\text {eq }}\left(\AA^{2}\right) \\ \mathrm{As}(1) & 11510(7) & 5075(5) & 21946(5) & 2 \cdot 4 \\ \mathrm{As}(2) & 27997(7) & 5764(5) & 6625(5) & 2 \cdot 3 \\ \mathrm{Cu}(1) & 0 & 0 & 0 & 2 \cdot 2 \\ \mathrm{Cu}(2) & 80410(10) & 16588(8) & 33116(9) & 4 \cdot 5 \\ \mathrm{Cl}(1) & 9579(2) & 933(1) & 4212(2) & 5 \cdot 2 \\ \mathrm{Cl}(2) & 6499(3) & 2380(2) & 2382(2) & 7 \cdot 8 \\ \mathrm{O}(1) & 1426(4) & 277(3) & 1445(3) & 2 \cdot 7 \\ \mathrm{O}(2) & 1271(4) & 151(3) & -142(3) & 2 \cdot 6 \\ \mathrm{C}(1) & 2854(7) & 924(5) & 3450(5) & 3 \cdot 2 \\ \mathrm{C}(2) & 2762(8) & 1494(5) & 3841(6) & 4 \cdot 0 \\ \mathrm{C}(3) & 4010(9) & 1771(5) & 4759(6) & 4 \cdot 9 \\ \mathrm{C}(4) & 5290(9) & 1493(5) & 5246(6) & 4 \cdot 8 \\ \mathrm{C}(5) & 5367(8) & 922(6) & 4830(6) & 4 \cdot 8 \\ \mathrm{C}(6) & 4128(7) & 625(5) & 3918(6) & 3 \cdot 7 \\ \mathrm{C}(7) & -301(7) & 1172(4) & 1469(5) & 2 \cdot 6 \\ \mathrm{C}(8) & -1000(7) & 1331(5) & 1773(6) & 3 \cdot 7 \\ \mathrm{C}(9) & -2035(8) & 1831(5) & 1203(7) & 4 \cdot 5 \\ \mathrm{C}(10) & -2368(9) & 2134(5) & 353(7) & 5 \cdot 0 \\ \mathrm{C}(11) & -1643(9) & 1965(5) & 61(7) & 4 \cdot 8 \\ \mathrm{C}(12) & -598(8) & 1477(5) & 626(6) & 3 \cdot 7 \\ \mathrm{C}(13) & 844(7) & -254(4) & 2664(5) & 2 \cdot 6 \\ \mathrm{C}(14) & 927(8) & -878(5) & 2380(6) & 3 \cdot 8 \\ \mathrm{C}(15) & 734(10) & -1428(5) & 2747(7) & 5 \cdot 5 \\ \mathrm{C}(16) & 459(9) & -1348(6) & 3365(7) & 5 \cdot 8 \\ \mathrm{C}(17) & 402(8) & -722(6) & 3645(6) & 5 \cdot 2 \\ \mathrm{C}(18) & 618(7) & -165(5) & 3307(5) & 3 \cdot 9 \\ \mathrm{C}(19) & 4235(7) & 75(4) & 1916(5) & 2 \cdot 7 \\ \mathrm{C}(20) & 3908(7) & -555(4) & 2005(5) & 3 \cdot 1 \\ \mathrm{C}(21) & 4968(8) & -935(5) & 2902(6) & 4 \cdot 4 \\ \mathrm{C}(22) & 6337(8) & -674(5) & 3678(6) & 4 \cdot 6 \\ \mathrm{C}(23) & 6658(8) & -34(6) & 3559(6) & 4 \cdot 7 \\ \mathrm{C}(24) & 5588(7) & 344(5) & 2654(6) & 3 \cdot 4 \\ \mathrm{C}(25) & 3294(6) & 681(4) & -116(5) & 2 \cdot 4 \\ \mathrm{C}(26) & 3993(7) & 1252(5) & 9(6) & 3 \cdot 8 \\ \mathrm{C}(27) & 4302(8) & 1320(6) & -589(6) & 5 \cdot 1 \\ \mathrm{C}(28) & 3921(7) & 831(6) & -1304(6) & 5 \cdot 0 \\ \mathrm{C}(29) & 3245(8) & 251(6) & -1404(6) & 5 \cdot 1 \\ \mathrm{C}(30) & 2939(7) & 180(5) & -795(5) & 3 \cdot 9 \\ \mathrm{C}(31) & 2619(6) & 1456(4) & 982(5) & 2 \cdot 9 \\ \mathrm{C}(32) & 1711(8) & 1873(5) & 125(7) & 5 \cdot 0 \\ \mathrm{C}(33) & 1527(9) & 2515(6) & 300(8) & 6 \cdot 3 \\ \mathrm{C}(34) & 2248(9) & 2725(5) & 1303(7) & 6 \cdot 2 \\ \mathrm{C}(35) & 3195(10) & 2311(6) & 2155(7) & 6 \cdot 4 \\ \mathrm{C}(36) & 3392(8) & 1651(5) & 1993(5) & 4 \cdot 3\end{array}$

Discussion. The structure consists of discrete $\left[\mathrm{Cu}^{\mathrm{II}}\left\{\mathrm{OAs}\left(\mathrm{C}_{6} \mathrm{H}_{5}\right)_{3}\right\}_{4}\right]^{2+}$ cations and $\left[\mathrm{Cu}^{\mathrm{I}} \mathrm{Cl}_{2}\right]^{-}$anions, as can be seen in Fig. 1 .

The $\mathrm{Cu}^{\mathrm{II}}$ ions are located at centres of inversion. Four organic ligands are coordinated to the metal, via oxygen, in a square-planar geometry, according to symmetry conditions. The rings of the organic part are planar within standard deviations. All distances and angles are normal. The most important bond distances and angles are indicated in Fig. 2.

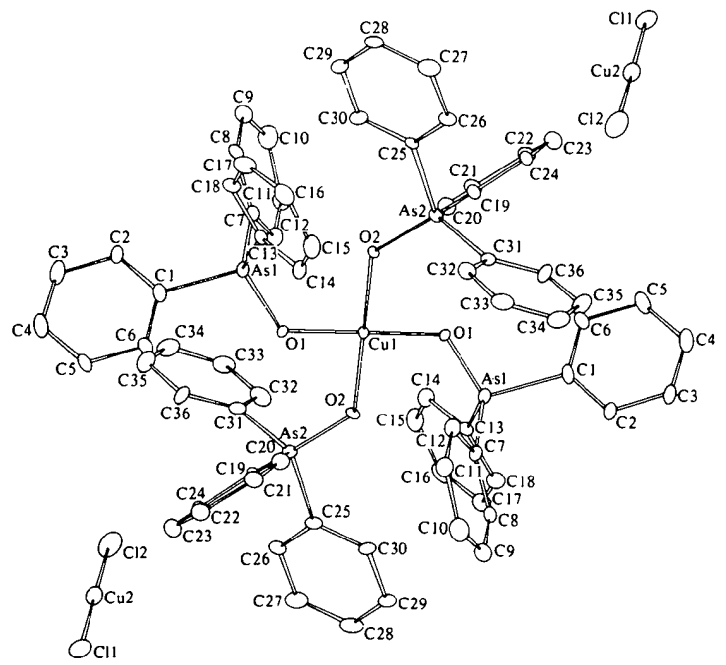

Fig. 1. Representation of the molecule giving atomic numbering.

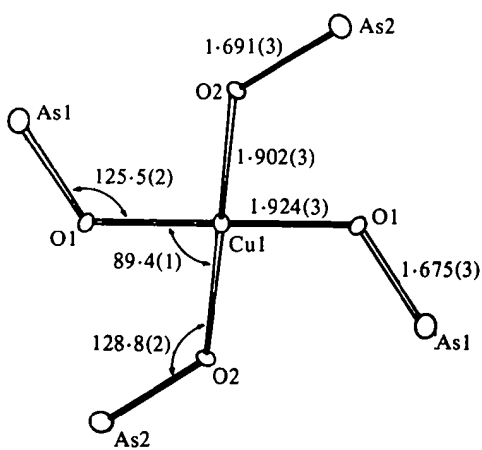

Fig. 2. Representation of the environment of the $\mathrm{Cu}^{11}$ ion with bond lengths $(\AA)$ and angles $\left({ }^{\circ}\right)$.

The dichlorocuprate ion is practically linear. The $\mathrm{Cu}-\mathrm{Cl}$ distance is 2.079 (2) $\AA$ for the two bonds and the central angle is $178.65(8)^{\circ}$.

The occurrence of this kind of ion in the solid state has been definitely established in chloro[dodecakis(dimethylamino)cyclohexa(phosphazene)- $N^{1}, N^{2}$,-

$N^{4}, N^{5}$ copper(II) dichlorocuprate(I) where the $\mathrm{Cu}-\mathrm{Cl}$ bond length is 2.06 (1) $\AA$ and the $\mathrm{Cl}-\mathrm{Cu}-\mathrm{Cl}$ angle is $179.5(9)^{\circ}$ (Marsh \& Trotter, 1971).

All computer calculations were performed using the Enraf-Nonius structure determination package. The figures were drawn with the ORTEP program (Johnson, 1965).

This work was sponsored by grants from BIDFINEP, CNPq and FAPESP. 


\section{References}

Germain, G., Main, P. \& Woolfson, M. M. (1971). Acta Cryst. A27, 368-376.

Goodgame, D. M. L. \& Cotton, F. A. (1961). J. Chem. Soc. pp. 2298-2304.

Hamilton, W. C. (1959). Acta Cryst. 12, 609-610.

International Tables for X-ray Crystallography (1974). Vol. IV. Birmingham: Kynoch Press.
JoHnson, C. K. (1965). ORTEP. Report ORNL-3794. Oak Ridge National Laboratory, Tennessee.

Marsh, W. C. \& Trotter, J. (1971). J. Chem. Soc. A, pp. $1482-1486$

Nyнolm, R. S. (1951). J. Chem. Soc. pp. 1767-1774.

Rodley, G. A., Goodgame, D. M. L. \& Cotton, F. A. (1965). J. Chem. Soc. pp. 14991505.

Acta Cryst. (1981). B37, 234-237

\title{
Cyano[3,3'-(1,3-propanediamino)bis(3-methyl-2-butanone oximato)]copper(II)- $\frac{1}{2}$-Acetonitrile
}

\author{
By E. O. Schlemper, M. Sakhawat Hussain and R. Kent Murmann \\ Department of Chemistry, University of Missouri, Columbia, Missouri 65211, USA
}

(Received 1 April 1980; accepted 19 August 1980)

\begin{abstract}
Cu}\left(\mathrm{C}_{13} \mathrm{H}_{27} \mathrm{~N}_{4} \mathrm{O}_{2}\right) \mathrm{CN}\right] \cdot \frac{1}{2} \mathrm{C}_{2} \mathrm{H}_{3} \mathrm{~N},[\mathrm{Cu}(\mathrm{CN})$ (pnao-H)].$\frac{1}{2} \mathrm{CH}_{3} \mathrm{CN}$, orthorhombic, Fdd $2, a=$ $18.993(2), b=32.352(2), c=11.799$ (1) $\AA, V=$ $7250.0 \AA^{3}, M_{r}=381.48, Z=16, \rho_{\text {calc }}=1.40(1)$, $\rho_{\text {obs }}=1.41$ (1) $\mathrm{Mg} \mathrm{m}^{-3}$. Three-dimensional counter $\mathrm{X}$-ray data were used to solve and refine the structure to a final $R\left(F^{2}\right)$ of 0.054 for 2600 independent reflections. The structure consists of discrete monomeric square-pyramidal $\mathrm{Cu}$ complex molecules with a strong intramolecular hydrogen bond. The a-amine-oxime ligand is quadridentate with an average $\mathrm{Cu}-\mathrm{N}$ (amine) distance $=2.043(3) \AA$ and $\mathrm{Cu}-\mathrm{N}$ (oxime) $=$ 1.978 (3) $\AA$. The cyanide ion is carbon bonded at the apical position with a $\mathrm{Cu}-\mathrm{C}$ bond distance of $2 \cdot 154(5) \AA$. The strong $\mathrm{Cu}-\mathrm{CN}$ bond pulls the $\mathrm{Cu}^{2+}$ ion out of the plane of the four $\mathrm{N}$ atoms by $0.499(6) \AA$. The short intramolecular hydrogen bond of 2.475 (4) $\AA$ is not appreciably modified by the presence of $\mathrm{CN}^{-}$. The acetonitrile molecule is not coordinated to the $\mathrm{Cu}^{\mathrm{II}}$ atom, but packs between the $\mathrm{Cu}$ complexes as solvent of crystallization.
\end{abstract}

Introduction. The deep-purple crystals (Murmann \& Monzyk, 1978) were consistently twinned when grown from aqueous media but gave satisfactory crystals from anhydrous acetonitrile. They crystallize with primarily $\{010\},\{011\}$, and $\{110\}$ facial development. The crystal selected was semi-spherical and had a volume of about $0.023 \mathrm{~mm}^{3}$. The space group and cell dimensions were first determined by precession film data, and the final cell dimensions were obtained with a Picker diffractometer from a least-squares refinement of the setting angles of 18 manually centered reflections. Intensity data were collected for 4094 reflections by the $\theta-2 \theta$ scan method using Mo $K a$ radiation $(\lambda=$ $0.7107 \AA$ ) filtered with $\mathrm{Nb}$. The data were corrected for background, $\mathrm{Lp}$ and absorption $\left(\mu=1.27 \mathrm{~mm}^{-1}\right){ }^{*}$ The transmission factor ranged from 0.89 to 0.73 . Standards monitored about every 75 reflections showed no significant systematic variation with time.

The structure was solved by Patterson and Fourier methods. The acetonitrile was revealed by a difference Fourier map and its occupancy factor refined to 0.5 . After a few cycles of least-squares refinement with all non-hydrogen atoms present, a difference Fourier map revealed most of the $\mathrm{H}$ atoms. When ambiguities occurred, idealized positions for these $\mathrm{H}$ atoms were calculated and were found to be consistent with difference Fourier peaks. Refinement was made using anisotropic temperature factors for all non-hydrogen atoms, with fixed $\mathrm{H}$ atoms. $\mathrm{H}$ atoms on the $\mathrm{CH}_{3} \mathrm{CN}$ molecule were treated as disordered around the twofold axis. Full-matrix refinement minimizing $\sum w\left(F_{o}^{2}-\right.$ $\left.k F_{c}^{2}\right)^{2}$, using 2600 independent reflections, 213 variables, scattering factors of Cromer \& Waber (1962), and anomalous scattering for $\mathrm{Cu}$ (Cromer, 1962), gave

* All calculations were performed on the University of Missouri IBM 370/168 computer system with the following programs: ANGSET (angle settings program); SORTH (sorting program; W. C. Hamilton); HORSE (general absorption-correction programs; W. C. Hamilton); FORDAP (Fourier synthesis program; A. Zalkin); NUCLS (least-squares program: R. Doedens and J. A. Ibers); a modification of ORFLS (Busing, Martin \& Levy, 1962); ORFFE (Busing. Martin \& Levy, 1964): ORTEP (Johnson, 1965).

(c) 1981 International Union of Crystallography 